Author's reply: Obsessive-compulsive disorder is classified as an anxiety disorder but our paper stated that our patients were free of other DSM-III-R axis I disorders. Increased brain 5-HT function may be associated with anxiety and our paper discussed this in the context of the hypothesis of Deakin et al (1991) that enhanced 5HT neurotransmission may serve to restrain 'flight' and enable coping in the presence of aversive cues. There was no correlation between illness severity in our patients and prolactin response to d-fenfluramine but this, perhaps, is not surprising given the small numbers of subjects and the likely complexity of the mechanisms involved.

In some anxiety disorders, for example panic disorder, increased prolactin responses to fenfluramine can be associated with anxiety provocation during the challenge test (Targum \& Marshall, 1989). However, as stated in our paper, these kind of subjective effects were not seen in our study. This makes a stress response in the patients an unlikely explanation for our findings (see Anderson et al, 1992).

Anderson, I. M., Ware, C. J., Da Roza Davis, J. M., et al (1992) Decreased 5-HT-mediated prolactin release in major depression. British journal of Psychiatry, 160. 372-378

Deakin, J. F. W., Graeff, F. G., Rodgers, R. J., et ol (1991) 5.HT and mechanisms of defence. journal of Psychopharmacology. 5, 305-315.

Targum, S. D. \& Marshall, L. E. (1989) Fenfluramine provocation of anxiety in patients with panic disorder. Psychiatry Research. 28. 295-306.

P. J. Cowen University Department of Psychiatry, Warneford Hospital, Oxford OX3 7JX

\section{Obsessional personality and outcome of panic disorder}

Sir: The letter of O'Rourke et al (1997) published in response to our letter earlier this year (Tyrer et al, 1997) has caused us considerable distress. More particularly, the penultimate paragraph suggesting that our observation that rural Irish patients may have greater symptom stability because of anancastic personalities is "a racist joke in poor taste" is something to which we take great exception.

This possible explanation of the findings was made in the spirit of scientific enquiry and contains no element of racism. The response of O'Rourke et al not only misrepresented our intentions but is also a slur on the reputation of another Irish colleague, Dr Kelleher, whose two publications on this subject were cited in our letter. In his 1972 paper (Kelleher, 1972) he showed that Irish general hospital patients chosen at random had significantly higher scores on the Leyton Obsessional Inventory than similar English equivalents, with an average score of 11 for the Irish subjects and 9.2 for the English ones. In the same paper he also showed that the rural Irish patients from the Cork area had scores which were 2.5 points higher than those who came from Cork city. In his 1982 paper (Scott et al, 1982) these findings were replicated, except that in addition a Scottish sample was compared and this was found to have lower obsessional scores than either the Irish or the English.

The reasons why we thought these findings may have significance in the study of O'Rourke et al (1996) is that in our own work we have found those who have anancastic personalities have fewer life events and show less diagnostic change than those who do not have such personalities. This is the background that led to our suggestion that rural Irish patients are more likely to have obsessional personality characteristics and that this could have clinical significance.

Kelleher, M. J. (1972) Cross-national (Anglo-Irish) differences in obsessional symptoms and traits of personality. Psychological Medicine, 2. 33-4l.

O'Rourke, D., Fahy, T. J., Bruphy, J., et al (1996) The Galway study of panic disorder. III: Outcome at 5 to 6 years. British journal of Psychiatry. 168. 462-469.

_, _, Prescott, P., et al (1997) Outcome of panic disorder (authors' reply). British journal of Psychiatry, 170. 89-90.

Scott, A., Kelleher, M. J., Smith, A., et al (1982) Regional differences in obsessionality and obsessional neurosis. Psychological Medicine, 12, 131-134.

Tyrer, P., Seivewright, N., Ferguson, B., et al (1997) Outcome of panic disorder (letter). British journal of Psychiatry. 170, 89.

P. Tyrer, N. Seivewright, B. Ferguson, T. Johnson Imperial College School of Medicine, St Mary's Campus, Paterson Centre, 20 Wharf Road. London W2 IPD

\section{Structural neuroimaging in learning disability}

Sir: We read with interest the recent article reviewing structural neuroimaging in learning disability (Deb, 1997). For adults with
Down's syndrome a strong association with dementia of Alzheimer's type is now well established. However, the review failed to discuss the role of structural neuroimaging in the detection of Alzheimer's disease in this population. Magnetic resonance imaging has demonstrated that subjects with Down's syndrome show signs associated with Alzheimer's disease; dilatation of ventricles, increased peripheral atrophy and increased deep white matter lesions (Pelz et al, 1986; Emerson et al, 1995). For subjects with Down's syndrome with clinical dementia, atrophic changes similar to those seen in the general population of those with Alzheimer's disease are found (Kesslak et al, 1994; Prasher et al, 1996) and non-specific basal ganglia changes are seen (Aylward et al, 1997). We agree with the author that structural neuroimaging holds great promise for future research, especially in the assessment of neurodegenerative disorders in those with learning disability.

Aylward, E. H., Li, Q., Habbak, R., et ol (1997) Basal ganglia volume in adults with Down syndrome. Psychiatric Research: Neuroımaging Section, 74, 73-82.

Deb, S. (1997) Structural neuroimaging in learning disability. British journal of Psychiatry. 17I, 417-419.

Emerson, J. F., Kesslak, J. P., Chen, P. C., et al (1995) Magnetic resonance imaging of the aging brain in Down syndrome. Progress in Clinical and Biological Research. 393. $123-138$.

Kesslak, J. P., Nagata, S. F., Lott, I., et al (1994) Magnetic resonance imaging analysis of age-related changes in the brain of individuals with Down's syndrome. Neurology. 44, 1039-1045.

Pelz, D. N., Karlik, S. J., Fox, A. J., et ol (1986) Magnetic resonance imaging in Down's syndrome. Canadian journal of Neurological Science, 13. 566-569.

Prasher, V. P., Barber, P. C., West, R., et al (1996) The role of magnetic resonance imaging in the diagnosis of Alzheimer's disease in adults with Down syndrome: case report. Archives of Neurology. 53. 1310-1313.

V. P. Prasher, E. Robertson Department of Psychiatry, University of Birmingham, Queen Elizabeth Psychiatric Hospital, Birmingham BI5 2QZ

\section{Variability in cognitive deterioration in schizophrenia}

Sir: Harvey et al (1995) report the failure to find deterioration in the mean Mini-Mental State Examination (MMSE; Folstein et al, 1975) scores of geriatric in-patients with schizophrenia over one- and two-year periods. Recently, we (Laws \& McKenna, 1996; Laws et al, 1998) have also found that people with chronic schizophrenia (as 